\title{
The Examination of Nutritional Status for Seniors Living in Social Institutions
}

I. Bartosovic (Ivan Bartosovic)¹, K. Zrubakova (Katarina Zrubakova)²,

P. Mikus (Peter Mikus)3, I. Sebova (Irina Sebova) ${ }^{4}$

${ }^{1}$ St. Elizabeth University of Health and Social Work, Bratislava, Slovakia.

${ }^{2}$ Faculty of Health, Catholic University, Ruzomberok, Slovakia.

${ }^{3}$ Faculty of Medicine, Slovak Medical University, Bratislava, Slovakia.

${ }^{4}$ Faculty of Medicine, Comenius University, Bratislava, Slovakia.

\section{E-mail address:}

ivan.bartosovic@gmail.com

\section{Reprint address:}

Ivan Bartosovic

Elizabeth University of Health and Social Work, Bratislava, Slovakia.

Nam.1. maja 1

81102 Bratislava

Slovakia

Source: Clinical Social Work and Health Intervention

Volume: 11

Issue: 3

Pages: $85-91$

Cited references: 31

\section{Reviewers:}

Mageswaari Rajoo

Bangkok, Thailand

Selvaraj Subramanian

SAAaRMM, Kuala Lumpur, Malaysia

\section{Keywords:}

Elderly. Nutrition. Institutions. Screening Tools. Malnutrition. Seniors. Mini Nutritional Assessment Short Form®. MNA-SF®.

\section{Publisher:}

International Society of Applied Preventive Medicine i-gap

CSWHI 2020; 11(3): 85 -91; DOI: 10.22359/cswhi_11_3_14 (C) Clinical Social Work and Health Intervention

\section{Abstract:}

Introduction: Elderly nutrition is affected by a variety of different factors. In the case of seniors living in institutional care nutrition remains underestimated although the nutritional status has a significant impact on their living in the institution and is an indicator of the quality of care.

Methodology: In March 2012, with the help of trained nurses we surveyed the nutritional status of all residents of the Seniors Facilities. As of 6 March 2012, there were 147 residents of av- 
erage age 79.4 years: the youngest resident was 58 years old; the oldest female resident was 94 years old. There were 103 women $(70.1 \%)$ with an average age of 80 years and 44 men (29.9\%) with average age 77.8 years. We examined all residents using the Mini Nutritional Assessment Short Form (MNA-SF®). Based on the results we have categorized them as: malnourished ( $0-7$ points); risk of malnutrition (8-11 points); normal nutritional status (12-14 points). The results in single categories were evaluated by chi-square test and by determining the level of significance $p$.

Results: When assessing nutrition through the MNA-SF® test, $51.7 \%$ of our seniors had normal nutritional status and over one third of the population $(34.7 \%)$ was at risk of malnutrition. Comparing the files by age (category $<80$ years versus category $\geq 80$ years) was statistically significant. Comparison of malnutrition and malnutrition risk scores ( $0-11$ points) versus the population of a normal dietary status (12-14 points) by age (category $<80$ years versus category $\geq 80$ years) was statistically significant.

Conclusion: Nutritional disorders are very common among seniors living in institutions. The nutritional status of our seniors living in social institutions is not optimal, with $34.7 \%$ of people at risk of malnutrition; $13.6 \%$ of malnourished people in our set. Regular nutritional assessment should be a routine activity allowing to identify early signs of nutritional disorder and to implement preventive measures.

\section{Introduction}

Elderly nutrition is affected by a variety of factors - biological, psychological, social and economic (Krajcik et al. 2016). In the living conditions of the population of the institutions, nutrition belongs to underestimated problems, although the nutritional status has a significant impact on their life in the facility and at the same time it is an indicator of the quality of care for the population (Bourdel-Marchasson 2010). Nutritional problems accompany the seniors even after their entry into the facility. Weight loss, malnutrition, obesity, diabetes, and sarcopenia are important disability factors in seniors and can drive older people to institutional care (BourdelMarchasson 2010). On the other hand, institutions should offer and implement differentiated nutritional care to: improve the quality of life; reduce functional disability; the risk of hospitalization; higher mortality among residents (BourdelMarchasson 2010). The environment of longterm institutions provides challenges and options for their solution (Castellanos 2004).

From the point of view of insufficient nutri- tion, hospitalized seniors and seniors in longterm institutional care constitute a risk group (Morley 2011, 2012). In a recently published meta-analysis including 240 studies with 113,967 older adult from different settings, prevalence of malnutrition according to the Mini Nutritional Assessment ${ }^{\circledR}$ was described to be: $3 \%$ in community-dwelling adults; $6 \%$ in older outpatients receiving home care; $18 \%$ in nursing home residents (Cereda et al. 2016). However, published prevalence data on malnutrition varies widely between studies even within specific setting probably due to different sampling characteristics and diagnostic criteria being used (Kiesswetter et al. 2019).

Diagnosis of malnutrition in seniors is based on a multidimensional assessment within a geriatric functional assessment. This includes: nutritional anamnesis; physical examination; anthropometric parameters; nutritional questionnaires; laboratory parameters; assessment of the functional state of muscle tissue (Guyonnet, Rolland 2015; Hoozová, 2015). During physical examination the body height and mass are monitored 
to calculate the Body Mass Index (BMI). However, the use of BMI in the elderly is affected by several factors. These include the fact that; elderly people cannot stand on the scales; the body height decreases; changes occur in body composition; fatty tissues change; BMI may not reveal sarcopenia; BMI cannot be determined because of the presence of swelling; vertebral fractures or limb losses; and so forth (Grzegorzewska et al . 2016; Babiarczyk, Turbiarz 2012).

The most commonly used screening and assessment tools for assessing the nutrition of seniors include; Subjective Global Assessment (SGA) (Detsky at el. 1987); Malnutritional Screening Tool (MST) (Ferguson et al. 1999); Nutritional Risk Screening (NRS 2002) (Kondrup et al. 2003); Malnutritional Universal Screening Tool (MUST) (Stratton et al. 2004); Simple Nutritional Assessment Questionnaire (SNAQ) (Wilson et al. 2005); Mini Nutritional Assessment (MNA®) (Guigoz et al. 1994); Mini Nutritional Assessment - Short Form (MNASF®) (Rubenstein et al. 2001).

The MNA® questionnaire is a complete form that includes 4 sets of questions and measurements (anthropometric measurements; overall assessment; dietary habits; eating habits; own health and nutritional assessment) (Guigoz et al. 1994; Vellas et al. 2006; Kaiser et al. 2009, 2011). In our work, we used a shortened version of the MNA questionnaire (MNA-SF®). This truncated version has been developed and tested for a common population of seniors, primarily in primary practice. The test length does not exceed 3 minutes. Sensitivity of MNA-SF® reached 97.9\%; specificity 100\% (Skates, Anthony 2012). The MNA-SF® questionnaire has two modifications when the sixth question indicates either the $\mathrm{BMI}$ or the calf circumference at the widest place (Skates, Anthony 2012). The authors of both versions of the MNA® questionnaire (full or shortened form) recommend a „two-step“ nutritional assessment, starting with a shortened form (MNA-SF®), and only in the case of pathology it is indicated to complete the MNA® questionnaire supplemented by laboratory examinations (Vellas et al. 2006, Kaiser et al. 2009). The MNA-SF® test is shown in Table 1.
Table $1 \mathrm{MNA}^{-S F^{\circledR}}$ test

\section{Mini Nutritional Assessment - Short Form} MNA - SF ${ }^{\circledR}$

A Has food intake declined over the past 3 months due to loss of appetite, digestive problems, chewing and swallowing difficulties?

1. severe decrease in food intake

2. moderate decrease in food intake

3. no decrease in food intake

B Weight loss during the last 3 months

1. weight loss greater than $3 \mathrm{~kg}$

2. does not know

3. weight loss between 1 and $3 \mathrm{~kg}$

4. no weight loss

\section{Mobility}

1. bed or chair bound

2. able to get out of bed / chair but does not go out

3. goes out

D Has suffered psychological stress or acute disease in the past 3 months?

1. yes

2. no

E Neuropsychological problems

1. severe dementia or depression

2. mild dementia

3. no psychological problems

F1 Body mass index (BMI), (weight in kg) / height in $\mathrm{m}^{2}$ )

1. BMI less than 19

2. BMI 19 to less than 21

3. BMI 21 to less than 23

4. BMI 23 or greater 23

OR

F2 Calf circumference (CC) in cm

1. CC less than 31

2. CC 31 or greater

\begin{tabular}{|cl|}
\hline \multicolumn{2}{|c|}{ Screening score } \\
$12-14$ points & normal nutritional status \\
$8-11$ points & at risk of malnutrition \\
$0-7$ points & malnourished \\
\hline
\end{tabular}




\section{Methodology}

In March 2012, with the help of the instructed nurses we examined the state of nutrition for all residents of the Seniors ' Facilities in Skalica. As of 6 March 2012, there were 147 residents of the average age of 79.4 years; the youngest resident was 58 years old; the oldest resident was 94 years old. There were 103 women $(70.1 \%)$ with an average age of 80 years; 44 men $(29.9 \%)$ with average age 77.8 years. The age category up to 80 years included $68(46.3 \%)$ seniors, the age category $\geq 80$ years contained 79 seniors $(53.7 \%)$. We examined all residents using the MNA-SF® test. For the four immobile residents we used F2 in the questionnaire - the circumference of the calf measured at the widest point. According to the results of the MNA-SF® test, we categorized the population as: malnourished ( $0-7$ points); at risk of malnutrition (8-11 points); normal nutritional status (12-14 points). The results in individual categories were evaluated by chi-square test and by determining the level of significance $p$.

\section{Results}

The nutritional status was evaluated using the MNA-SF® test. In our set, $51.7 \%$ of the popula- tion had a normal nutritional status of and more than a third of the population $(34.7 \%)$ was at risk of malnutrition (Table 2).

Table 2 Nutritional status determined by the MNA-SF ${ }^{\circledR}$ test

\begin{tabular}{|l|c|}
\hline \multicolumn{2}{|c|}{$\begin{array}{l}\text { Nutritional status as determined by MNA-SF } \\
(\mathrm{n}=147)\end{array}$} \\
\hline $\begin{array}{l}\text { Malnourished } \\
\text { (0-7 points) }\end{array}$ & $20(13.6 \%)$ \\
\hline $\begin{array}{l}\text { At risk of malnutrition } \\
\text { (8-11 points) }\end{array}$ & $51(34.7 \%)$ \\
\hline $\begin{array}{l}\text { Normal nutrition } \\
\text { (12-14 points) }\end{array}$ & $76(51.7 \%)$ \\
\hline
\end{tabular}

Table 3 shows the evaluation of the MNA$\mathrm{SF}$ 囚 test by sex and age. File comparison by gender was not statistically significant. Comparing files by age category $(<80$ years to category $\geq$ 80 years) was statistically significant. The comparison of malnutrition and malnutrition risk scores ( $0-11$ points) versus the population of normal nutritional status (12-14 points) by age category ( $<80$ years to the category $\geq 80$ years) was statistically significant (Table 3 ).

Table 3 Nutritional status of the residents by gender and age as determined by MNA-SF ${ }^{\circledR}$ test

\begin{tabular}{|c|c|c|c|c|c|c|c|c|}
\hline $\begin{array}{c}\text { Results } \\
\text { of }{\mathrm{MNA}-\mathrm{SF}^{\oplus}}^{\oplus} \text { test }\end{array}$ & $\begin{array}{c}\text { Men } \\
(n=44)\end{array}$ & $\begin{array}{l}\text { Women } \\
(n=103)\end{array}$ & $x^{2}$ & $p$ & $\begin{array}{c}\text { Age }<80 y . \\
(n=68)\end{array}$ & $\begin{array}{c}\text { Age } \geq 80 y . \\
(n=79)\end{array}$ & $x^{2}$ & $p$ \\
\hline $\begin{array}{l}\text { Malnourished } \\
\text { (0-7 points) }\end{array}$ & 7 (15.9\%) & $13(12.6 \%)$ & 1.56 & 0.458 & $10(14.7 \%)$ & $10(12.7 \%)$ & 7.14 & 0.028 \\
\hline $\begin{array}{c}\text { At risk of } \\
\text { malnutrition } \\
\text { (8-11 points) }\end{array}$ & $12(27.3 \%)$ & 39 (37.9\%) & & & $16(23.5 \%)$ & 35 (44.3\%) & & \\
\hline $\begin{array}{c}\text { Normal } \\
\text { nutritional } \\
\text { status } \\
\text { (12-14 points) }\end{array}$ & $25(56.8 \%)$ & 51 (49.5\%) & & & 42 (61.8\%) & $34(43 \%)$ & & \\
\hline $\begin{array}{l}\text { Malnourished } \\
\text { and at risk of } \\
\text { malnutrition } \\
\text { (0-11 points) }\end{array}$ & $19(43.2 \%)$ & 52 (50.5\%) & 0.66 & 0.416 & $26(38.2 \%)$ & 45 (57\%) & 5.13 & 0.023 \\
\hline $\begin{array}{c}\text { Normal } \\
\text { nutritional } \\
\text { status } \\
\text { (12-14 points) }\end{array}$ & $25(56.8 \%)$ & $51(49.5 \%)$ & & & 42 (61.8\%) & $34(43 \%)$ & & \\
\hline
\end{tabular}




\section{Discussion}

Sitna in her doctoral work focused on malnutrition in a population of 124 residents in social care facilities in six towns in the Central Bohemian Region who had an average age of 78.9 years. According to her results: $7.6 \%$ of the population in the institutions suffered from malnutrition; $21.7 \%$ of the population were at risk of malnutrition; $70.6 \%$ of population had a good nutritional status (Sitna, 2009). Our results are worse with $48.3 \%$ of seniors at risk of malnutrition or malnutrition.

De Luis et al. used the MNA-SF® questionnaire in a subset of 873 patients over 65 years living in Spanish institutions. The normal nutritional category included: $42.1 \%$ of the population; $57.9 \%$ of the residents were at risk of malnutrition (De Luis et al. 2011).

Kaiser et al. evaluated the nutritional status of seniors living in the community, nursing homes and rehabilitation facilities in Germany and Italy. The category of normal nutritional status encompassed: $37.4 \%$ of the population; $39.2 \%$ of the seniors were at risk of malnutrition; $23.4 \%$ of the population were in the malnutrition category (Kaiser et al. 2011).

The Ostrava authors surveyed the nutritional status of seniors in long-term illnesses, inpatient departments, homes for seniors, and homes for seniors with a special regime. In the investigated group, $30 \%$ of seniors suffered from malnutrition, $38 \%$ were at risk of malnutrition and $32 \%$ were in good a nutritional condition (Luksova, Vrublova 2014).

The authors compared the nutrition of seniors living in the community in urban and rural settings and residents of nursing homes in Poland. In a set of 859 inhabitants of seven institutions: $38.5 \%$ of the population were in normal nutritional status; $44.5 \%$ of the population were at the risk of malnutrition; $17 \%$ of the nursing home residents were in the group of malnutrition (Kostka et al. 2014). Our results are similar.

Juhasova et al. (2016) evaluated the state of nutrition in homes for seniors. The MNA® test found that: $42.3 \%$ of the elderly were in the normal diet; $37.1 \%$ at the risk of malnutrition; $20.6 \%$ of the seniors were found in malnutrition. With increasing age, the risk of malnutrition increased in this study. A higher risk of malnutrition was seen in older people aged over 85 . We have achieved similar results in our set. The authors conclude that Mini Nutritional Assessment is simple, valid and useful screening tool for valuation of elderly people living in the retirement homes (Juhasova et al. 2016).

\section{Conclusion}

Nutritional disorders are very common among seniors living in institutions. The nutritional status of our seniors living in social institutions is not optimal: $34.7 \%$ of people at risk of malnutrition; $13.6 \%$ of malnourished people in our set.

Regular assessment of nutritional status should be routine to identify early signs of nutritional disorders and to implement preventive measures. In daily practice every elderly should be screened for nutritional deficiencies: during preventative visits; at every hospitalization; at entering long-term institution and home care service (Topinkova 2003).

\section{References:}

1. BABIARCZYK B, TURBIARZ A (2012) Body Mass index in elderly people - do the reference ranges matter? Prog Health Sci; 2(1): 58-67.

2. BOURDEL-MARCHASSON I (2010) How to improve nutritional support in geriatric institutions. J Am Med Dir Assoc; 11:13-20. DOI: 10.1016/j.jamda.2009.04.003.

3. CASTELLANOS VH (2004) Food and nutrition in nursing homes Generations 28(3): 65-71.

4. CEREDA E, PEDROLLI C, KLERSY C et al (2016) Nutritional status in older persons according to healthcare setting: a systematic review and meta-analysis of prevalence data using Clin Nutr; 35, 1282-1290.

5. DETSKY AS, MC LAUGHLIN JR, BAKER JP et al (1987) What is subjective global assessment of nutritional status? J Parenter Enteral Nutr; 11(1): 8-13.

6. DE LUIS DA, LOPEZ MONGIL R, GONZALES SAGRADO M et al (2011) Evaluation of the mini-nutritional assessment short form (MNA-SF®) among institutionalized older patients in Spain. Nutr Hosp 26 (6): 1350-1354.

7. FERGUSON M, CAPRA S, BAUER J et al (1999Development of a valid and reliable 
malnutrition screening tool for adult acute hospital patients. Nutrition; 15(6): 458-464.

8. GRZEGORZEWSKA A, WOLEJKO K, KOWALKOWSKA A et al (2016) Proper $B M I$ ranges for the elderly in the context of morbidity, mortality and functional status. Gerontologia Polska; 24: 114-118.

9. GUIGOZ Y et al (1994) Mini Nutritional assessment: A practical assessment tool for grading the nutritional state of elderly patients. Facts Research in Gerontology Suppl 2: $15-59$

10. JAROSOVA E, VAREKOVA J, STEFFL M, FINE J (2019) Physical and nutritional education in general rehabilitation of individuals after mixture damage. In: Rehabilitation, vol. 56, no. 4, 2019, ISSN 0375-0922, pp. 188-198.

11. GUIGOZ Y (2006) The Mini-Nutritional Assessment (MNA®) Review of Literature What does it tell us? J Nutr Health Aging 10: 466-487.

12. GUYONNET S, ROLLAND Y (2015) Screening for malnutrition in older people. Clin Geriatr Med 31: 429-437. DOI 10.1016/j.cger.2015.04.009.

13. HOOZOVA J (2015) Malnutrition in elderly. Paliat. med. lieč. bol. 8(1e): e6-e12.

14. JUHASOVA I, POKORNA A, MIKLASOVA I et al (2016) Nutritional screening carried out by nurses in retirement home. Geriatrie a gerontologie 2016; 5(3): 122-127.

15. KAISER MJ, BAUER JM, RAMSCH C et al (2009) Validation of the Mini Nutritional Assessment Short-Form (MNA®-SF): A practical tool for identification of nutritional status. J Nutr Health Aging 13: 782-788.

16. KAISER MJ, BAUER JM, UTER W et al (2011) Prospective validation of the modified Mini Nutritional Assessment Short-Forms in the community, nursing home and rehabilitation setting. JAGS; 59(11): 2124-2128.

17. KIESSWETTER E， COLOMBO MG, MEISINGER CH et al (2019) Malnurition and related risk factors in older adults from different health-care setting: an enable study. Public Health Nutrition; DOI: https://doi.org/10.1017/S1368980019002271

18. KONDRUP J, RASMUSSEN HH, HAMBERG O et al.ad hoc (2003) Espen working group. Nutritional risk screening (NRS
2002): a new method based on an analysis of controlled clinical trials. Clin Nutr; 22(3): 321-336.

19. KOSTKA J, BOROWIAK E, KOSTKA T (2014) Validation of the modified Mini Nutritional Assessment Short Forms in different populations of older people in Poland. The Journal of Nutrition, Health and Aging; 18(4): 366-371.

20. KRAJCIK S, MIKUS P, BAJANOVA E et al (2018) Nutrition in advanced age. Bratislava Herba 192 p. ISBN 978-80-89631-84-1.

21. BURDOVA A, RAJCOKOVA, M, BARNA M (2015) Quality standards of social services in the Slovak Republic. Health and Social Work. ISSN 13336-9326. 10, 2015, no. 2, p. 19-26.

22. LUKSOVA H, VRUBLOVA Y (2014) The nutritional status of the elderly in institutional care. Hygiena; 59(1): 17-20.

23. MORLEY JE (2011) Assessment of malnutrition in older persons: a focus on the Mini $\mathrm{Nu}$ tritional Assessment. J Nutr Health Aging; 15(3): 87-90.

24. MORLEY JE (2012) Undernutrition in older adults. Family Practice; 29: i89-i96, doi: 10.1093/famprac/cmr054.

25. RUBENSTEIN LZ, HARKER JO, SALVA A et al (2001) Screening for Undernutrition in Geriatrice Practice: Developing the ShortForm Mini Nutritional Assessment (MNASF®). J Gerontol A Biol Sci Med Sci; 56(6): M366-372.

26. SITNA D (2009) Malnutrition in residents of homes for seniors. Doctoral work. Faculty of health care and social work University in Trnava $97 \mathrm{p}$.

27. SKATES JJ, ANTHONY PS (2012) Identifying geriatric malnutrition in nursing practice. The Mini Nutritional Assessment (MNA®) -an evidence -based screening tool. Journal of Gerontological Nursing 38(3): 1827.

28. STRATTON RJ, HACKSTON A, LONGMORE D et al (2004) Malnutrition in hospital outpatients and inpatients: prevalence, concurrent validity and ease of use of the „malnutrition universals screening tool“ (MUST) for adults. Br J Nutr; 92: 799-808.

29. TOPINKOVA E (2003) The use of standardized assessment scales for evaluation of nu- 
tritional status in older patients. Czech geriatric review 1: 6-11.

30. VELLAS B, VILLARS H, ABELLAN G et al (2006) Overview of the MNA® - Its History and Challenges. J Nutr Health Aging 10: 456-465.
31. WILSON MM, THOMAS DR, RUBENSTEIN LZ et al (2005) Appetite assessment: simple appetite questionnaire predicts weight loss in community-dwelling adults and nursing home residents. Am J Clin Nutr 82(5): 1074-1081. 